This document is the accepted manuscript version of the following article:

Milic, A., Miljevic, B., Alroe, J., Mallet, M., Canonaco, F., Prevot, A. S. H., \& Ristovski, Z. D. (2016). The ambient aerosol characterization during the prescribed bushfire season in Brisbane 2013. Science of the Total Environment, 560-561, 225-232. https://doi.org/10.1016/ j.scitotenv.2016.04.036

This manuscript version is made available under the CC-BY-NC-ND 4.0 1icense http://creativecommons.org/1icenses/by-nc-nd/4.0/

\title{
The ambient aerosol characterization during the prescribed bushfire season in Brisbane 2013
}

\author{
A. Milic ${ }^{\mathrm{a}}$, B. Miljevic ${ }^{\mathrm{a}}$, J. Alroe ${ }^{\mathrm{a}}$, M. Mallet ${ }^{\mathrm{a}}$, F. Canonaco ${ }^{\mathrm{b}}$, A. S.H. Prevot ${ }^{\mathrm{b}}$ and Z.D. Ristovski ${ }^{\mathrm{a}}$ \\ a International Laboratory for Air Quality and Health, Queensland University of Technology, 2 George Street, \\ Brisbane, QLD 4001, Australia \\ ${ }^{\mathrm{b}}$ Paul Scherrer Institute, Laboratory of Atmospheric Chemistry, 5232 Villigen PSI, Switzerland
}

\begin{abstract}
Prescribed burnings are conducted in Queensland each year from August until November aiming to decrease the impact of bushfire hazards and maintain the health of vegetation. This study reports chemical characteristics of the ambient aerosol, with a focus on source apportionment of the organic aerosol fraction (OA), during the prescribed biomass burning (BB) season in Brisbane 2013. All measurements were conducted within the International Laboratory for Air Quality and Health (ILAQH) located in Brisbane's Central Business District. Chemical composition, degree of ageing and the influence of BB emission on the air quality of central Brisbane were characterized using a compact Time of Flight Aerosol Mass Spectrometer (cToF-AMS). AMS loadings were dominated by OA (64 \%), followed by, sulfate (17\%), ammonium (14\%) and nitrates (5\%). Source apportionment was applied on the AMS OA mass spectra via the multilinear engine solver (ME-2) implementation within the recently developed Source Finder ( $\mathrm{SoFi}$ ) interface. Six factors were extracted including hydrocarbon-like OA (HOA), cooking-related OA (COA), biomass burning OA (BBOA), lowvolatility oxygenated OA (LV-OOA), semivolatile oxygenated OA (SV-OOA), and nitrogen-enriched OA (NOA). The aerosol fraction that was attributed to BB factor was $9 \%$, on average over the sampling period. The high proportion of oxygenated OA (72 \%), typically representing aged emissions, could possess a fraction of oxygenated species transformed from BB components on their way to the sampling site.
\end{abstract}

Keywords: Air quality, Biomass burning, Organic aerosol, Aerosol mass spectrometry, Source apportionment

\section{Introduction}

Biomass burning (BB) aerosol mostly originates from domestic heating sources, natural fires, as well as from prescribed burning. BB aerosol has significant influence on human health, global climate and environment (Luhar et al., 2008; van der Werf et al., 2006). Burning emissions encompass a variety of gaseous and particle-phase species, including primary aerosols released directly from the sources in the atmosphere and secondary aerosols generated through the gas-to-particle conversion processes of primary gaseous compounds. Smoke plumes are considered as one of the largest contributors to the primary carbonaceous particles in the atmosphere, which include organic carbon (OC) and black carbon (BC) (Bond et al., 2004; Hallquist et al., 2009). Moreover, once emitted in the atmosphere, the volatile portion of primary BB aerosol is subject to atmospheric photochemical ageing processes and is likely to be a large source of secondary organic aerosol (SOA) precursors (DeCarlo et al., 2010; Grieshop et al., 2009; Heringa et al., 2011; Jimenez et al., 2009). In order to identify aerosol of BB origin, different chemical markers have been suggested. Anhydrosaccharides, levoglucosan-like species (levoglucosan, mannosan, galactosan), are organic molecules formed during pyrolysis of carbohydrates and common components of BB plumes (Simoneit et al., 1999). Many studies have suggested levoglucosan as a valuable BB chemical signature (Jordan et al., 2006; Simoneit, 2002; Simoneit et al., 1999), although using it as the only indicator has been questioned due to its suggested

\footnotetext{
${ }^{1}$ Corresponding Author:

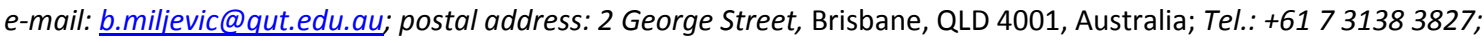


semivolatile nature and non-inert behaviour in the atmosphere (Hoffmann et al., 2009; May et al., 2012).

Levoglucosan produces a prominent signal at $\mathrm{m} / \mathrm{z} 60$ (fragment $\mathrm{C}_{2} \mathrm{H}_{4} \mathrm{O}_{2}{ }^{+}$) and $\mathrm{m} / \mathrm{z} 73$ (fragment $\mathrm{C}_{3} \mathrm{H}_{5} \mathrm{O}_{2}^{+}$) of the mass spectrum extracted from Aerosol Mass Spectrometer (AMS) data (Aiken et al., 2008; Alfarra et al., 2007; Cubison et al., 2011). The AMS has found an application in real-time mass spectral analysis of quantitative aerosol chemical composition as well as particle size. Originally, the AMS has been designed for investigation of submicron non-refractory (NR) chemical species (species that are flash-vaporized at the AMS heater temperature of approximately $600{ }^{\circ} \mathrm{C}$ ). A fragmentation table is used to attribute fragments into the major species; organics (Org), nitrates $\left(\mathrm{NO}_{3}{ }^{-}\right)$, sulfates $\left(\mathrm{SO}_{4}{ }^{2-}\right)$, ammonium $\left(\mathrm{NH}_{4}{ }^{+}\right)$and chloride $\left(\mathrm{Cl}^{-}\right)$. The fraction of an organic fragment signal, e.g. $\mathrm{m} / \mathrm{z} 60$, to total organic mass is useful in characterizing the aerosol and is referred to as $f 60 . f 60$ and $f 73$ typically represent levoglucosan-based markers in the presence of BB emissions. According to Cubison et al. (2011), a $f 60$ value higher than 0.003 indicates substantial BB aerosol contribution. The parameter $f 60$ is a signature of primary wood burning emissions. Moreover, Heringa et al. (2011) has suggested that SOA formed through ageing processes of BB-related volatile organic compounds also contributes to non-negligible amounts of $f 60$. Many studies have demonstrated the same trend of $f 60$ decreasing and $f 44$, the parameter related to the oxygenated organic aerosol fraction (OOA), increasing with ageing (Capes et al., 2008; Cubison et al., 2011; Grieshop et al., 2009; Jolleys et al., 2015; Ng et al., 2010b; Ortega et al., 2013; Zhao et al., 2014). Thus, the ratio of $f 44$ and $f 60$ indicates the photochemical evolution of BB aerosol over time and fresh BB aerosol can be distinguished from aged, highly oxidized species.

Considering the multiple primary and secondary sources, it is a big challenge to apportion organic aerosol (OA) into its sources. The positive matrix factorization (PMF) technique (Paatero and Tapper, 1994) has been demonstrated to produce meaningful source apportionment results of AMS data (Lanz et al., 2007a; Ulbrich et al., 2009). This local minimum multivariate factor analytical model creates a linear combination of static factor profiles (OA mass spectra) and their contributions over time. The number of factors is highly subjective and needs exploration by the experimentalist. In addition, PMF solutions are known to suffer from rotational ambiguity, i.e. similar solutions with an equal degree of fit may exist (Paatero et al., 2002). This requires an accurate investigation of the solution space, differing the number of factors (different type of aerosol species), applying rotations in the solution space ( $a$ value) and using different starting conditions (seed runs). Within these runs, it is generally possible to find the solution that "best" explains the data (Canonaco et al., 2013; Ulbrich et al., 2009). In comparison to the chemical mass based method where factors are completely constrained, the PMF algorithm does not allow any a priori information to be applied. The multilinear engine algorithm (ME-2) technique introduced by Paatero (1999) and Paatero and Hopke (2009), however, allows different options to be tested using factor profiles and/or time series applied to different constrained degrees. A graphical user interface, SoFi (Source Finder), outlined in Canonaco et al. (2013) applies the ME-2 algorithm using predetermined profiles aiming to facilitate application of different rotational approaches and to retrieve the solution closest to the "true" solution. One approach to applying constraints involves utilization of the $a$ value method first introduced by Lanz et al. (2007b) for AMS data. The $a$ value typically ranges from 0 for the completely constrained case, to 1 . Different $a$ values correspond to different deviations from input factor profile and/or time series, e.g. an applied $a$ value of 0.3 means that $30 \%$ of the profile/time series can be varied by the algorithm during the minimization process. Factors that do not show significant variability are considered primary factors including hydrocarbon-like OA (HOA), cooking-related OA (COA) and biomass burning OA (BBOA). Secondary profiles, low-volatility oxygenated OA (LV-OOA) and semivolatile oxygenated OA (SV-OOA), can be highly dependent on features of the environment and thus prone to different degrees of aerosol evolution. Secondary factors, in contrast to primary, are therefore likely not suitable for the constraint method if specific conditions are not known (Canonaco et al., 2015).

Annual prescribed biomass burning in Queensland is conducted at the end of winter and over the spring months (from August until November), in order to mitigate wildfire hazards and preserve the vegetation. Prescribed burns are planned based on local conditions including the weather and impact 
on people and animals. This study reports and interprets an ambient dataset sampled during Brisbane's prescribed bushfire season from a ground-based sampling site, which can be classified as urban background due to its location in Central Business District (CBD). Collected data were characterized using the cToF-AMS with a focus on OA apportionment, done within the SoFi package, employing the ME-2 engine and using the $a$ value constraining approach (Canonaco et al., 2013; Crippa et al., 2014). Source apportionment of the BB aerosol allowed us to assess the contribution of these yearly fires to the aerosol signal in the Brisbane CBD.

The ambient aerosol characterization for the same sampling site has been conducted using the cToFAMS (Crilley et al., 2014b), but was not performed in continuous measurement during the specific period of the prescribed fires. This work is an important step in characterizing biomass burning aerosol in the Brisbane CBD, a densely populated city area. Furthermore, it will contribute to a wider understanding of $\mathrm{BB}$ characteristics in subtropical urban environments, which have not been significantly explored in the southern hemisphere.

\section{Experimental}

\subsection{Sampling site}

The ambient measurements took place at the Queensland University of Technology (QUT) campus, located in the Brisbane CBD. All the used instrumentation was located in the International Laboratory for Air Quality and Health (ILAQH) laboratory (27²8'38.5968'S, $153^{\circ} 1^{\prime} 40.8828^{\prime \prime}$ ). The ambient sampling was conducted during the Queensland prescribed bushfire season, from the $29^{\text {th }}$ of August to the $3^{\text {rd }}$ of October 2013, with a break of two weeks due to instrument malfunction. The bushfire locations were obtained from the Queensland Fire and Rescue Service archive (https://www.fire.qld.gov.au/). A considerable area of Brisbane was affected by bushfire events with 24 fires identified during the measurement period (Figure 1). Most of prescribed fires took place during the first sampling period (from $29^{\text {th }}$ of August to $4^{\text {th }}$ of September) with most of them close to the sampling laboratory (up to $50 \mathrm{~km}$ in distance). The second period (from $20^{\text {th }}$ of September to $3^{\text {th }}$ of October) was characterized by a small number of mostly remote burned areas.

Apart from BB plumes, contribution from the traffic sources is significant for this sampling site (around 150 m distance away from a main motorway, the Riverside Expressway), as well as emissions from the industrial part of Brisbane (port and oil refineries). The biogenic species emitted from the City Botanic Gardens and the Brisbane river that surround the monitoring location could also considerably affect the aerosol content (Figure 1) (Crilley et al., 2014b). 


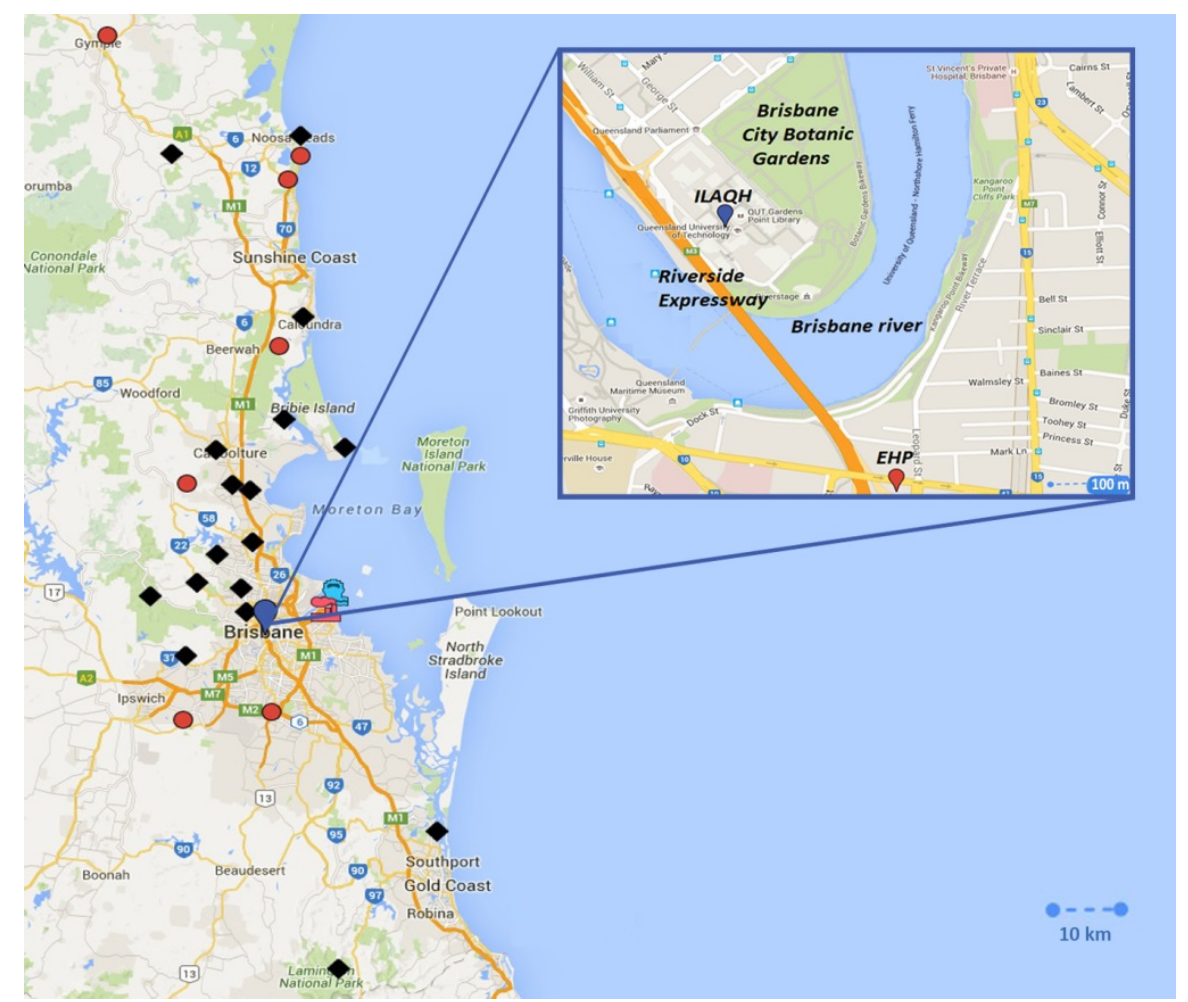

Figure 1. Bushfire locations that were identified during the first period (black diamonds) and the second measurement period (red circles) along with labels for the ILAQH sampling site (blue mark), the port of Brisbane and oil refineries. In addition, a local map of the ILAQH sampling site environment (including EHP location) is shown.

\subsection{Instrumentation}

An Aerodyne compact Time of Flight Aerosol Mass Spectrometer (cToF-AMS) was deployed to monitor the chemical composition of submicron ambient aerosol. Detailed description of the instrument's operation can be found elsewhere (Canagaratna et al., 2007; Drewnick et al., 2005; Jimenez et al., 2003). Particle number concentration and size distribution were monitored by a Scanning Mobility Particle Sizer (SMPS) consisting of a TSI 3080 Electrostatic Classifier and a TSI 3010 Condensation Particle Counter. The SMPS was measuring in a configured particle size range from 7.6 to $310.6 \mathrm{~nm}$ in diameter in 3 minute intervals. Ozone concentrations were measured in 1 minute time resolution using an Ecotech (EC9810) Ozone Monitor. Standard meteorological parameters, including ambient temperature, relative humidity, wind speed and wind direction, were obtained from the Department of Environment and Heritage Protection (EHP) monitoring station located at South Brisbane (2729'5.4960”S, 153 1'56.0028”E) (Figure 1). The station also provided supporting ambient air quality data for carbon monoxide (CO) and nitrogen oxides $\left(\mathrm{NO}_{\mathrm{X}}\right)$. All parameters were recorded over 30-minute intervals.

\section{Data Analysis}

The AMS dataset was processed in the Wavemetrics Igor Pro software (Version 6.36) using the standard ToF-AMS Analysis Toolkit named Squirrel (Version 1.55H). A modified fragmentation table (Aiken et al., 2008), was applied to the AMS unit mass resolution data. This fragmentation table was adjusted using information from the background aerosol composition, obtained through filter measurements at the beginning of the measurement period. Collection efficiency (CE) was estimated based on the procedure discussed in Middlebrook et al. (2012) by incorporating ammonium nitrate, organic content and aerosol acidity. The composition dependent collection efficiency was found to be 0.5 for the majority of the samples, so this value was used in all calculations. In order to estimate the 
degree of oxidation for each factor, oxygen-to-carbon ratio $(\mathrm{O} / \mathrm{C})$ was calculated from the $\mathrm{f} 44$ value, using the relation suggested by Aiken et al. (2008) (Aiken-ambient $\mathrm{O} / \mathrm{C}$ values, "O/ $\mathrm{C}_{\mathrm{A}-\mathrm{A}}$ "), as well as the "improved-ambient" equation (Improved-ambient $\mathrm{O} / \mathrm{C}$ values, "O/C $\mathrm{C}_{\mathrm{I}-\mathrm{A}}$ "), recently introduced by Canagaratna et al. (2014).

The SoFi toolkit (Version 5.3) was applied to investigate the solution space, and identify and quantify contributions of the main OA sources extracted using the ME-2. The number of possible solutions was investigated without applying any a priori information (completely unconstrained PMF run). Subsequently, the HOA, COA and BBOA factor profiles identified in first dataset were used to constrain the solution space for the whole data set. Finally, the $a$ value approach was performed by applying a combination of $a$ values ranging from 0 to 0.1 for HOA and COA and from 0 to 0.5 for BBOA (in increments of 0.1), as suggested by Crippa et al. (2014). Stronger constraints were examined on HOA and COA profiles compared to BBOA, as the BB-related factor profile can vary more depending on burning material, combustion conditions and environment (Weimer et al., 2008).

\section{Results and discussion}

\subsection{Meteorological and ambient data}

The ambient measurement study was conducted during Brisbane's spring months, with average relative humidity and temperature values of $66 \%$ and $24{ }^{\circ} \mathrm{C}$, respectively (Error! Reference source not found.). Daily variation in wind direction showed the characteristic breeze pattern for the Brisbane environment (Error! Reference source not found. and Error! Reference source not found.) (Morawska et al., 2002). Land breezes (primarily SSW land breeze - 170-230 ${ }^{\circ}$ ) were observed during the night and morning hours, from 12pm to 11am, while between midday and midnight winds were mostly blowing from the ocean (NE, E and SE breeze - 40-140 ). The daily ocean breeze was characterized by speeds up to $5 \mathrm{~m} / \mathrm{s}$ higher than the night wind (Error! Reference source not found.). Substantially increased particle number concentrations were observed in the weekday morning hours (Error! Reference source not found. and Error! Reference source not found.). The morning wind direction was predominately SSW indicating the Riverside Expressway as the main particle source (approximately $150 \mathrm{~m} \mathrm{~S}$ from the measurement site). In addition, morning cleaning activities within the university campus occurred every working day from 5 to $7 \mathrm{am}$, with cleaning occurring in front of the measurement site around 6am. Vacuum cleaners and leaf blowers were used. Aerosol emitted during the peak afternoon traffic period was not detected by the SMPS as the wind was typically blowing from the sampling location towards the River Expressway. CO and $\mathrm{NO}_{\mathrm{X}}$ measured by the EHP-operated station followed the same daily trend of increased values during morning hours (Error! Reference source not found. and Error! Reference source not found.), but demonstrated an increase during the afternoon traffic hour due to the EHP location (Figure 1). Ozone time profiles show a clear characteristic increase during the day (Error! Reference source not found. and Error! Reference source not found.). Concentrations fluctuated between a nightly minimum of nearly zero and up to $60 \mathrm{ppb}$ during the ozone peak period, between noon and 3pm, with an average value of $20 \mathrm{ppb}$.

\subsection{Aerosol composition (AMS data)}

The ambient NR submicron aerosol was mainly composed of OA $(63.7 \% \pm 3.8)$ with an average concentration of $4.21 \mathrm{\mu g} \mathrm{m}^{-3}$. Particles also consisted of a substantial amount of sulfate $(16.6 \% \pm$ 1.0), ammonium $(14.1 \% \pm 1.1)$, and nitrates $(5.3 \% \pm 0.4)$ with the respective average concentrations of $1.12 \mu \mathrm{g} \mathrm{m}^{-3}, 1.00 \mu \mathrm{g} \mathrm{m}^{-3}, 0.42 \mu \mathrm{g} \mathrm{m}^{-3}$ and a negligible average chloride contribution of $0.01 \mu \mathrm{g} \mathrm{m}$ $(0.2 \% \pm 0.1)$ (Figure 2a andFigure 2b). 


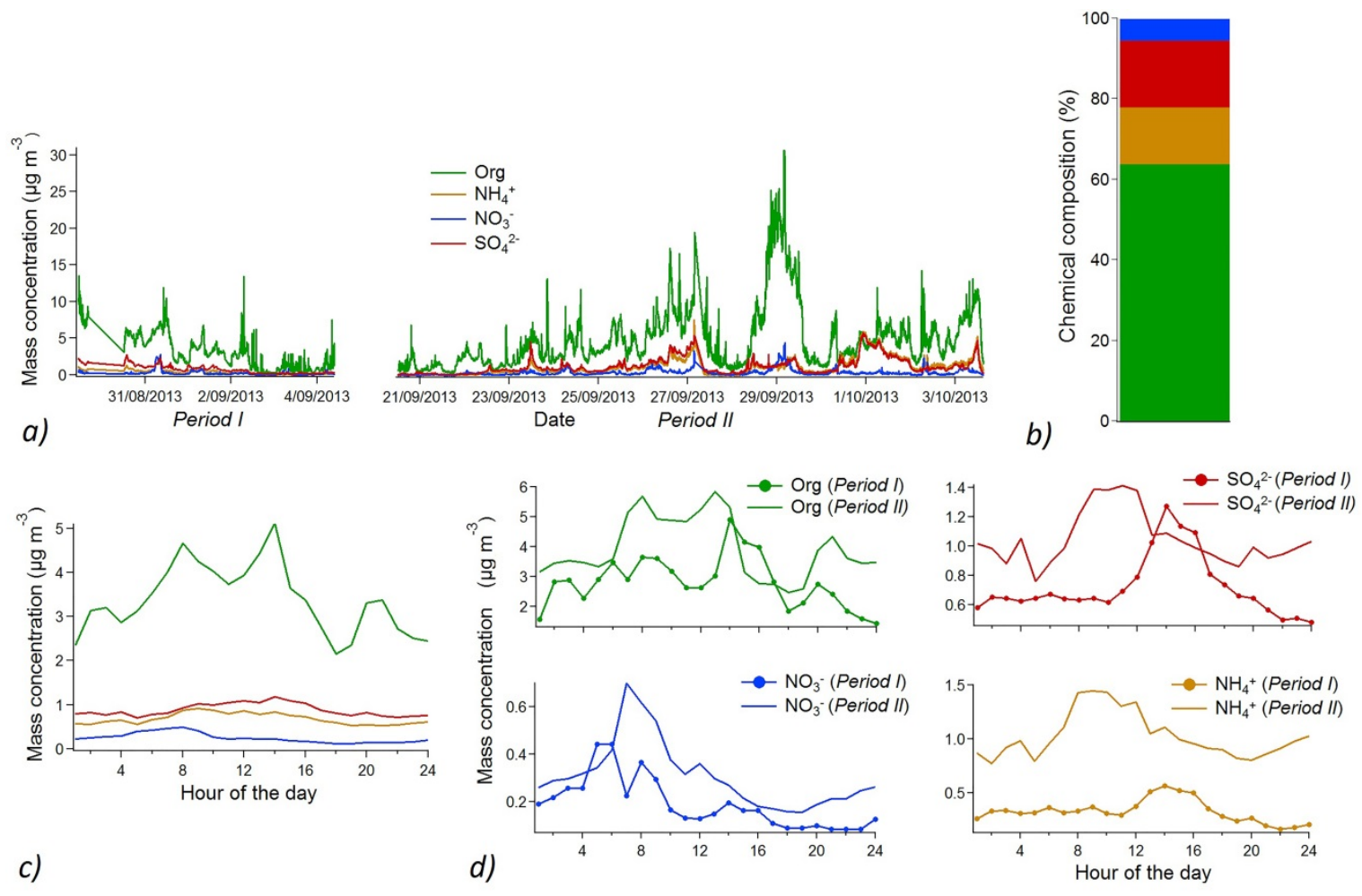

Figure 2. Time series (a) and relative contribution (b) of AMS NR species for the whole sampling period, along with their diurnal trends looking at both sampling periods together (c) and separately (d), where Period I and Period II correspond to the first (29/08/13 - 04/09/13) and the second (20/09/13 - 03/10/13) measurement period and the straight line at the beginning of the measurement represents a 6h gap. As chloride concentrations were not significant they were excluded from graphs.

Diurnal trends of NR AMS components for the overall measurement campaign, as well as for the first and the second time period separately, are given in Figure 2c and Figure 2d, respectively. The diurnal pattern of the measured organic mass illustrates its high variation during the sampling period, with morning, afternoon and evening peaks. Diurnal cycles of inorganic NR species demonstrate similar trends in sulfate and ammonium concentrations, while nitrates had a distinctly different trend which suggested different sources of ammonium sulfate and nitrate. Considering the sulfate concentration in the first time interval, the diurnal trend showed a maximum extending from noon till late afternoon. During this period easterly breezes were predominant (Error! Reference source not found.), likely carrying sulfates from marine aerosols and industrial and port emissions. The diurnal trend for the second period is not as distinct, compared to the first one. From Figure 2d it can be seen that, during the afternoon hours of period two, sulfates have very similar concentrations as during the afternoon hours of period one, suggesting that ocean breezes and industrial and port emissions contribute to sulfate detection in both periods. However, another source seemed to be more dominant during the morning hours of the second period. During these hours $(7 \mathrm{am}-1 \mathrm{pm})$, land breezes were prevalent (Error! Reference source not found.) and we could not relate sulfate masses to any particulate source. Similar diurnal patterns were observed in sulfate and organics for both sampling periods.

\subsection{2 $\mathrm{f} 44 \mathrm{vs}$. $\mathrm{f} 60$ plot}

The contribution of BB aerosols and their ageing degree for both sampling periods are illustrated in the $\mathrm{f} 44$ vs. f60 space (Figure 3). According to the proportion of points exceeding the f60 background limit of 0.003 (55\% and 35\% for the first and the second period respectively), more aerosols with BB origin were detected during the first period. This was expected due to the higher proportion of close fires that occurred in the first sampling period. 
Fresh BB aerosols can be distinguished from aged, oxidized species by different $\mathrm{f} 44$ values (Figure 3). $\mathrm{Ng}$ et al. (2010b) illustrated that aged aerosol has f44 values mostly between 0.1 and 0.25 . According to that, the majority of the aerosols detected during this campaign were highly processed. It is clear that the second period was characterized by a higher proportion of oxidized species, compared to the first period. $17 \%$ of the sampled aerosol in the second period had f44 above 0.25 indicating a high contribution of aged aerosol. This difference in the proportion of aged aerosol between the periods could be attributed to mostly distant fires in the second period.
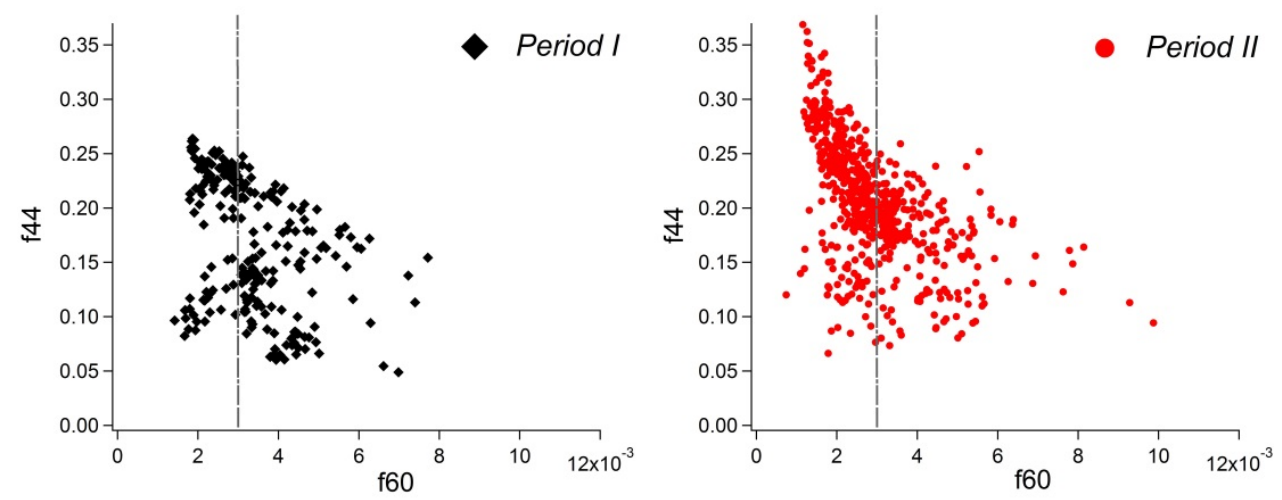

Figure 3. f44 vs. f60 space with dots colored by sampling period (data were averaged over the 30-min interval for better illustration; gray line on the graphs illustrates f60 background limit of 0.003)

\subsection{Source Apportionment}

Organic matter was found to be the most abundant NR-PM1 component (64\%) of the total AMS mass that was measured during the campaign. In order to identify and quantify OA sources and estimate the contribution of BB-related source for the Brisbane urban area, the ME-2 apportionment technique using SoFi was applied. There was a gap of two weeks in the sampling due to instrument malfunction. In order to estimate all possible solutions and identify reasonable sources of the sampled aerosol, datasets generated before and after the break were analyzed separately and together. Addressing datasets separately did not result in factor solutions that were consistent across both datasets. More details can be found in Error! Reference source not found.. Further analysis was done by performing PMF on the merged datasets.

\subsubsection{Unconstrained PMF run (combined datasets)}

An unconstrained PMF run was performed on the whole dataset with the number of factors ranging from 1 to 10 and applying 10 iterations (seeds). More details can be found in Error! Reference source not found.. The 6-factor solution was found to best explain the data as a lower number of factors did not give a full explanation of the dataset and seven or more factors resulted in splitting of existing profiles (Error! Reference source not found.). The solution with 6 factors included: two primary components, hydrocarbon-like OA (HOA) and cooking-related OA (COA); two OOA factors, low-volatility oxygenated OA (LV-OOA) and semivolatile oxygenated (SV-OOA); biomass burning $\mathrm{OA}(\mathrm{BBOA})$; and nitrogen-enriched $\mathrm{OA}$ (NOA). In the following paragraphs, the selection of this 6factor solution will be supported and explained in details. The profile, time series and diurnal pattern of the extracted factors are presented in Error! Reference source not found..

The HOA and COA factors in the 6-factor solution were well separated, compared to solutions with lower number of factors where these primary sources were merged into one profile, with recognizable $\mathrm{m} / \mathrm{z}$ 41, 43, 55, 57 related to alkyl ion peaks (Error! Reference source not found.). Both signals m/z 55 and 57 were attributed to primary OA emitted from combustion sources. The COA factor can be distinguished from HOA when the $\mathrm{m} / \mathrm{z} 55$ signal is dominant over $\mathrm{m} / \mathrm{z} 57$, as observed here and in many other studies (Allan et al., 2010; Mohr et al., 2012; Sun et al., 2011). The peaks during typical 
meal times (prominent lunch and dinner-related peaks), present in the COA diurnal profile (Error! Reference source not found.b and Error! Reference source not found.c), provide further evidence of cooking aerosol contribution, as previously observed (Allan et al., 2010). The diurnal trend of the common factor (HOA+COA) in solutions with less than 6 factors encompassed both the HOA-related morning rush hour peak and the COA-related evening peak (Error! Reference source not found.a). On the other hand, the 6-factor solution allowed successful apportionment of these peaks to HOA and COA respectively (Error! Reference source not found.b). There was a clear diurnal trend in the COA factor that illustrated meal periods during the day and intensive cooking contribution in the evening hours. The cooking aerosol contribution was more significant during weekend evenings, rather than during weekdays, due to increased restaurant patronage in the Brisbane CBD. The morning traffic peak in the HOA factor disappeared during weekends, when there was less traffic volume (Error! Reference source not found.c).

When choosing 6 factors, oxygenated OA was separated into two components, LV-OOA and SVOOA, that are characterized by different degrees of oxidation and volatility, as illustrated in many other studies (Jimenez et al., 2009; Lanz et al., 2007a; Ng et al., 2010b; Ulbrich et al., 2009). LVOOA was characterized by a unique factor profile with a prominent $\mathrm{m} / \mathrm{z} 44$ signal and strong diurnal trend showing increased levels during midday hours, due to enhanced photochemical activity in the atmosphere. SV-OOA had a less prominent $\mathrm{m} / \mathrm{z} 44$ signal and significant $\mathrm{m} / \mathrm{z} 43$ contributions compared to LV-OOA, which indicated less oxidized and often more volatile species. Contribution of SV-OOA decreased from midday to the evening hours consistent with the temperature increase and relative humidity decrease. This might be explained by gas-phase partitioning of the more volatile fraction with temperature increase (Budisulistiorini et al., 2013; Canonaco et al., 2015; Crippa et al., 2014; Lanz et al., 2007a).

The BBOA factor was identified by the prominence of levoglucosan-related ions, m/z 60 and 73 . However, there was no observed clear apportionment of its other important m/z's. More precisely, it seemed that $\mathrm{m} / \mathrm{z} 43$ and $\mathrm{m} / \mathrm{z} 44$, which belong to the BBOA factor, were apportioned to other factor profile. The BBOA diurnal trend is marked by a broad daily peak which indicates the usual time of prescribed burnings.

The last factor, identified in the selected solution, was assumed to be a nitrogen-enriched organic factor (NOA). The main ion signals were $\mathrm{m} / \mathrm{z} 42,44,56$ and 58. The NOA profile was not marked with ions $\mathrm{m} / \mathrm{z}$ 30, 46 and 86 , which have been related to nitrogen organic species. A similar NOA spectrum was observed and associated with marine sources and/or industrial activities that produce amino compounds (Sun et al., 2011). The observed wind was from the SW (Error! Reference source not found.) and did not coincide with the direction of the industrial zone (NE) or the ocean (E, NE, SE). Therefore this uniform trend couldn't be related to a specific source. NOA's distinctive diurnal trend was characterized by a broad peak starting after midnight and continuing until approximately $8 \mathrm{am}$. Increases in the NOA factor were in agreement with increases in relative humidity and decreases in ambient temperature, as previously observed by Carbone et al. (2014). High relative humidity and low temperature could provide a suitable environment for low molecular weight and highly watersoluble amines to stay in particle phase. This was in contrast to the daytime peak observed by Sun et al. (2011), suggesting that photooxidation reactions were not the primary driving force of NOA production for this study. Another possible solution is that semivolatile aminium salts from ocean air masses condensed over the night when high relative humidity and low temperature are taking place. More research is needed to characterize and identify the source(s) of this component.

Performing PMF on the merged datasets resulted in a common factor solution which encompassed the factors that were extracted when PMF was performed on datasets separately. This included SV-OOA profile which was not seen in the separate 6-factor solutions from each period. There was also successful separation of HOA and COA when PMF was applied on the whole dataset, which was not the case for the second set of data alone. The unconstrained 6-factor solution, obtained from the merged dataset, was therefore chosen for further analysis. 


\subsubsection{Issues with unconstrained PMF run}

As stated, the 6-factor solution provided the most representative set of factors, however, there was significant apportionment of the oxidized fraction to the HOA and COA profiles $\left(\mathrm{O} / \mathrm{C}_{\mathrm{A}-\mathrm{A}}\right.$ of 0.25 and 0.26, respectively) (Error! Reference source not found.) compared to the values reported for the same sampling site in the Crilley et al. (2014b) study and primary profiles in other studies (DeCarlo et al., 2010; Jimenez et al., 2009; Ng et al., 2010b). Another issue was an unclear mass spectrum profile of the BBOA component (Error! Reference source not found.). In order to improve these extracted profiles, ME-2 was applied using the a priori information. Factor profiles identified within the analyzed dataset were considered to be more representative of sources of interest than profiles obtained in other studies. In order to improve HOA, COA and BBOA profiles using a priori information, factor profiles generated by running unconstrained PMF separately on the first and second time periods were considered.

Looking at the 5-factor solution for the first dataset, the HOA and COA profiles did not have a significant amount of m/z $44\left(\mathrm{O} / \mathrm{C}_{\mathrm{A}-\mathrm{A}}\right.$ of 0.19 and 0.08 , respectively) (Error! Reference source not found.). On the other hand, in the second period, HOA and COA were characterized by high O/C values $\left(\mathrm{O} / \mathrm{C}_{\mathrm{A}-\mathrm{A}}\right.$ of 0.30 and 0.21 , respectively), similar to values from the combined dataset. The COA diurnal trend was less distinct and the HOA afternoon peak had significant cooking contribution in the evening hours for the second set of data (Error! Reference source not found.) compared to the first period where factors were better separated (Error! Reference source not found.). The BBOA spectrum identified in the first dataset was characterized with all typical m/z's (Error! Reference source not found.), while the BBOA in the second dataset did not have a clear factor profile (Error! Reference source not found.). The latter suggested that HOA, COA and BBOA factor profiles revealed in the first dataset could be used as a priori information for further analysis.

\subsubsection{Constrained $a$ value approach}

HOA, COA and BBOA, generated for the first data period, were set as constrained factor profiles for the whole dataset. The constrained model was applied on the 6-factor solution, previously chosen for further analysis. The two dimensional $a$ value approach was performed for HOA/COA and BBOA, ranging from 0 to 0.1 and from 0 to 0.5 respectively, in increments of 0.1 , as suggested by (Crippa et al., 2014). The rest of the factors were not predetermined and were allowed to freely change and thus adapted to minimize the weighted residuals, as in the classical, unconstrained PMF. The selection of the solution was made based on changes in the factors' mass spectra, correlation of factors with compatible external data and diurnal trends of HOA and COA components. Identified profiles for different applied $a$ values (model runs) are presented in Figure 4. 


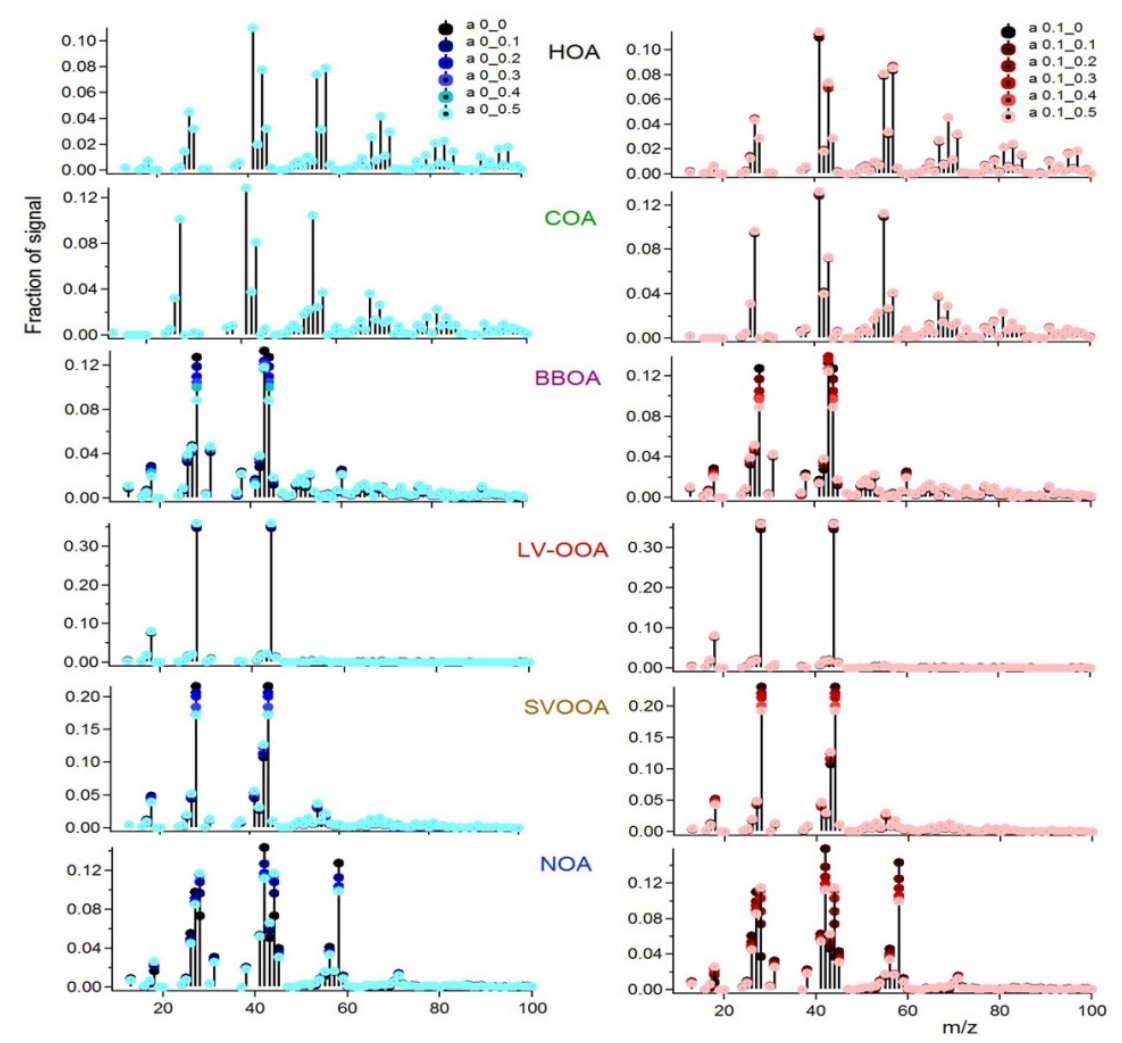

Figure 4. Mass spectra of the 6-factor solution profiles for different a value combinations are presented. Each model run is illustrated with a different color. Solutions on the left-hand side comprise factors generated by applying an a value of 0 to $\mathrm{HOA}$ and $\mathrm{COA}$, and a values ranging from 0 to 0.5 for $\mathrm{BBO}$. Solution on the right hand side comprises factors generated when a value of 0.1 was applied on HOA and $\mathrm{COA}$, and a values ranging from 0 to 0.5 for $B B O A$.

HOA and COA profiles did not vary as more tightly constrained models were applied. The mass spectra of the BBOA constrained profile varied with different $a$ values, with the greater change occurring when constraints were more relaxed, as expected. The unconstrained profiles showed also significant variation, especially the SV-OOA and NOA profiles. These variations were primarily seen in $\mathrm{m} / \mathrm{z} 43$ and $\mathrm{m} / \mathrm{z}$ 44. BBOA and SV-OOA do not possess strong metrics and hence, in particular $\mathrm{m} / \mathrm{z}$ 43 in the profile of BBOA and SV-OOA is anticorrelated.

The diurnal trend of the HOA factor stayed stable following each model run, while there were minor changes in the COA trend (Error! Reference source not found.). General enhancement in the cooking contribution was observed when the BBOA profile was more constrained ( $a$ value was increased).

Correlations of retrieved factor time series with corresponding traces were made separately for the first and second period, due to different environmental features between two time periods (Error! Reference source not found. and Error! Reference source not found.). The different locations of the EHP monitoring station and ILAQH sampling site meant that the $\mathrm{NO}_{\mathrm{x}}$ and $\mathrm{CO}$ data were not representative as external tracers for correlation analysis. However, there were similarities in the diurnal trends of the $\mathrm{HOA}$ factor, $\mathrm{NO}_{\mathrm{X}}$ and $\mathrm{CO}$, showing a morning peak (Error! Reference source not found.).

BBOA and Org 60 had good correlations in both sampling intervals, with $\mathrm{R}^{2}$ (Pearson) value of 0.9 and 0.4 , for the first and the second period respectively. As previously mentioned this discrepancy can probably be attributed to locations of BB events. In the second period, emissions from predominately 
remote fires may have resulted in more oxidized species and less aerosol with BB features. Previous studies have reported a correlation between two low-volatile secondary species, LV-OOA and $\mathrm{SO}_{4}$ (Lanz et al., 2007a; Ulbrich et al., 2009). In this study this correlation was stronger in the first period $\left(\mathrm{R}^{2}\right.$ of approximately 0.8 ) compared to the second period $\left(\mathrm{R}^{2}\right.$ of approximately 0.4$)$. In the first period, the direct influence of ocean breezes and industrial emissions contributed to detection of secondary sulfate. A similar conclusion cannot be drawn for the second period, when the exact source of sulfate was not known. Moreover, the difference in LV-OOA/sulfate as well as in SV-OOA/nitrate correlations between the periods agrees with observations made by Crippa et al. (2014) that OOA profiles have different correlations with secondary inorganic compounds depending on the sampling environment.

Although increasing $a$ value from 0 to 0.5 for BBOA profile (in both applied $a$ values for COA/HOA) led in general to the decrease of overall correlations between factors and corresponding markers, there was no considerable difference observed. Moreover, HOA/COA diurnal patterns did not vary significantly. Thus the average of all the considered solutions was taken as the final best solution, considering the spread (Error! Reference source not found.). As expected, the values of the spread were lower for constrained profiles than for profiles that were left to freely change. OOA profiles showed the highest variation.

\subsubsection{Comparison of the unconstrained and constrained solutions}

Application of the constrained $a$ value approach enabled extraction of factor solutions in which the BBOA profile was well apportioned with all typical m/z's, as compared to the unconstrained case (Error! Reference source not found.). Unlike the unconstrained solution, the $\mathrm{O} / \mathrm{C}_{\mathrm{A}-\mathrm{A}}$ values in the constrained case (Error! Reference source not found.) were observed to be comparable to the $\mathrm{O} / \mathrm{C}_{\mathrm{A}-\mathrm{-}}$ A values for previously reported profiles $\left(\mathrm{O} / \mathrm{C}_{\mathrm{A}-\mathrm{A}}\right.$ for $\mathrm{HOA}$ and $\mathrm{COA}$ were 0.18 and 0.12 , respectively). This result was made without compromising HOA and COA diurnal trends that still showed good apportionment according to morning HOA and lunch and evening COA peaks (Error! Reference source not found.). Negligible changes were observed in the two solutions when looking at the relative contribution of HOA, COA and NOA profiles. The $a$ value approach also resulted in negligible decrease in the overall contribution of OOA, however, distribution of LV-OOA and SVOOA was changed from $56 \%$ and $19 \%$ to $42 \%$ and $31 \%$ for LV-OOA and SV-OOA respectively. More OA was apportioned to the BBOA factor when constraints were applied (from $5 \%$ to $9 \%$ ).

The aforementioned improvements supported the use of this constrained solution for the final OA source apportionment.

\section{4 $\mathrm{BB}$ aerosol contribution and ageing}

Source apportionment attributed $9 \%$ of the OA to the BB-related factor. During a study in Brisbane that estimated the effect of ultrafine particles from traffic emissions on children's health, two measurement sites that were $10 \mathrm{~km}$ away from each other, measured significantly different BBOA percentage contribution (26\% and $10 \%$ ) during the same season (within the prescribed burning period) in different years (2011 and 2012) (Crilley et al., 2014a). Furthermore, another Brisbane study performed measurements at our sampling site (Crilley et al., 2014b), outside of the prescribed burning period, and reported larger BB aerosol contributions (13\%) than has been observed in this study. This suggests that contribution of BB aerosol for the Brisbane urban area varies depending on the year, and more precisely on the frequency, intensity and location of fires and direction of their pathways.

The $\mathrm{O} / \mathrm{C}_{\mathrm{A}-\mathrm{A}}$ ratio for $\mathrm{BBOA}$ was significantly higher compared to previous results $\left(\mathrm{O} / \mathrm{C}_{\mathrm{A}-\mathrm{A}}\right.$ of 0.25$)$ for the same sampling site (Crilley et al., 2014b), suggesting that this factor includes partially aged BB emissions. Aged BBOA factors with $\mathrm{O} / \mathrm{C}$ ratios comparable to this study have previously been reported in other BB campaigns (Bougiatioti et al., 2014; Brito et al., 2014). Furthermore, OOA components contributed the highest percentage of OA mass (72 \%) from all identified factors. Thus it is possible that BB-related aerosol lost their signature characteristics on their way to the sampling site due to the high oxidation of levoglucosan-like species. The atmospheric processing probably led to 
oxidation of OA towards LV-OOA with the BB-signature being replaced with an oxidation signature as suggested in Jimenez et al. (2009).

As can be seen from Error! Reference source not found., LV-OOA and SV-OOA factors are characterized with unusually high $\mathrm{O} / \mathrm{C}_{\mathrm{A}-\mathrm{A}}$ values (1.44 and 0.67 , respectively) compared to reported results for the Northern Hemisphere ( 0.73 and 0.35 respectively) ( $\mathrm{Ng}$ et al., 2010b) and for subtropical urban area of Mexico City that is at the same latitude as Brisbane (0.83 and 0.52 , respectively) (Aiken et al., 2008). However, similarly high $\mathrm{O} / \mathrm{C}_{\mathrm{A}-\mathrm{A}}$ ratios have been already observed in the Brisbane area (Crilley et al., 2014a). This once more suggests high contributions of SOA and confirms the importance of ageing processes for central Brisbane air quality.

\section{Conclusion}

The influence of the prescribed bushfire season on air quality was investigated through source apportionment analysis of AMS data. The contribution of BB-related aerosol was 9\%, suggesting limited influence of BB events on the central Brisbane area air quality. One explanation may be that BB plumes were not completely apportioned due to mixing with background urban aerosol and intensive ageing on their way to the sampling site. In this case processed BB emissions could have contributed to the high proportion of OOA components (72\%). Another possibility is that a limited number of smoke plumes were coming towards the Brisbane CBD.

The high OOA contributions are in line with a prior Brisbane study, further suggesting intense photochemical ageing of aerosol in the central Brisbane area. Moreover, the high OOA proportions highlight the importance of SOA for this location.

Application of the recently developed SoFi interface, using the ME-2 algorithm, improved the final solution space when comparing factors generated before and after applying constraints. Both primary (HOA and COA) and secondary (LV-OOA and SV-OOA) factors were revealed by applying the unconstrained PMF method to the separate studied periods, but their profiles would not have been successfully apportioned over the entire period without constraining the primary source profiles.

\section{Acknowledgements}

This work was supported by the Australian Research Council Discovery grant (DP120100126). We would like to thank Don Neale for providing valuable ambient data measured by the Department of Environment and Heritage Protection (EHP) monitoring station.

\section{Supplementary data}

Supplementary data to this article can be found online at http://dx.doi.org/10.1016/j.scitotenv.2016.04.036.

\section{References}

Aiken AC, DeCarlo PF, Kroll JH, Worsnop DR, Huffman JA, Docherty KS, et al. O/C and OM/OC ratios of primary, secondary, and ambient organic aerosols with high-resolution time-of-flight aerosol mass spectrometry. Environmental Science \& Technology 2008; 42: 4478-4485.

Alfarra MR, Prevot AS, Szidat S, Sandradewi J, Weimer S, Lanz VA, et al. Identification of the mass spectral signature of organic aerosols from wood burning emissions. Environmental science \& technology 2007; 41: 5770-5777.

Allan J, Williams P, Morgan W, Martin C, Flynn M, Lee J, et al. Contributions from transport, solid fuel burning and cooking to primary organic aerosols in two UK cities. Atmospheric Chemistry and Physics 2010; 10: 647-668. 
Bond TC, Streets DG, Yarber KF, Nelson SM, Woo JH, Klimont Z. A technology-based global inventory of black and organic carbon emissions from combustion. Journal of Geophysical Research: Atmospheres (1984-2012) 2004; 109.

Bougiatioti A, Stavroulas I, Kostenidou E, Zarmpas P, Theodosi C, Kouvarakis G, et al. Processing of biomass-burning aerosol in the eastern Mediterranean during summertime. Atmospheric Chemistry and Physics 2014; 14: 4793-4807.

Brito J, Rizzo L, Morgan W, Coe H, Johnson B, Haywood J, et al. Ground-based aerosol characterization during the South American Biomass Burning Analysis (SAMBBA) field experiment. Atmospheric Chemistry and Physics 2014; 14: 12069-12083.

Budisulistiorini SH, Canagaratna MR, Croteau PL, Marth WJ, Baumann K, Edgerton ES, et al. Real-time continuous characterization of secondary organic aerosol derived from isoprene epoxydiols in downtown Atlanta, Georgia, using the Aerodyne Aerosol Chemical Speciation Monitor. Environmental science \& technology 2013; 47: 5686-5694.

Canagaratna $M$, Jayne J, Jimenez J, Allan J, Alfarra $M$, Zhang $Q$, et al. Chemical and microphysical characterization of ambient aerosols with the aerodyne aerosol mass spectrometer. Mass Spectrometry Reviews 2007; 26: 185-222.

Canagaratna M, Jimenez J, Kroll J, Chen Q, Kessler S, Massoli P, et al. Elemental ratio measurements of organic compounds using aerosol mass spectrometry: characterization, improved calibration, and implications. Atmospheric Chemistry and Physics Discussions 2014; 14: 19791-19835.

Canonaco F, Crippa M, Slowik J, Baltensperger U, Prévôt A. SoFi, an IGOR-based interface for the efficient use of the generalized multilinear engine (ME-2) for the source apportionment: ME2 application to aerosol mass spectrometer data. Atmospheric Measurement Techniques 2013; 6: 3649-3661.

Canonaco F, Slowik J, Baltensperger U, Prévôt A. Seasonal differences in oxygenated organic aerosol composition: implications for emissions sources and factor analysis. Atmospheric Chemistry and Physics 2015; 15: 6993-7002.

Capes G, Johnson B, McFiggans G, Williams P, Haywood J, Coe H. Aging of biomass burning aerosols over West Africa: Aircraft measurements of chemical composition, microphysical properties, and emission ratios. Journal of Geophysical Research: Atmospheres (1984-2012) 2008; 113.

Carbone S, Aurela M, Saarnio K, Saarikoski S, Timonen H, Frey A, et al. Wintertime Aerosol Chemistry in Sub-Arctic Urban Air. Aerosol Science and Technology 2014; 48: 313-323.

Crilley LR, Ayoko GA, Morawska L. First measurements of source apportionment of organic aerosols in the Southern Hemisphere. Environmental Pollution 2014a; 184: 81-88.

Crilley LR, Jayaratne ER, Ayoko GA, Miljevic B, Ristovski Z, Morawska L. Observations on the formation, growth and chemical composition of aerosols in an urban environment. Environmental science \& technology 2014b; 48: 6588-6596.

Crippa M, Canonaco F, Lanz V, Äijälä M, Allan J, Carbone S, et al. Organic aerosol components derived from 25 AMS data sets across Europe using a consistent ME-2 based source apportionment approach. Atmospheric Chemistry and Physics 2014; 14: 6159-6176.

Cubison M, Ortega A, Hayes P, Farmer D, Day D, Lechner M, et al. Effects of aging on organic aerosol from open biomass burning smoke in aircraft and laboratory studies. Atmospheric Chemistry and Physics 2011; 11: 12049-12064.

DeCarlo P, Ulbrich I, Crounse J, Foy Bd, Dunlea E, Aiken A, et al. Investigation of the sources and processing of organic aerosol over the Central Mexican Plateau from aircraft measurements during MILAGRO. Atmospheric Chemistry and Physics 2010; 10: 5257-5280.

Drewnick F, Hings SS, DeCarlo P, Jayne JT, Gonin M, Fuhrer K, et al. A new time-of-flight aerosol mass spectrometer (TOF-AMS)-Instrument description and first field deployment. Aerosol Science and Technology 2005; 39: 637-658. 
Grieshop A, Logue J, Donahue N, Robinson A. Laboratory investigation of photochemical oxidation of organic aerosol from wood fires 1: measurement and simulation of organic aerosol evolution. Atmospheric Chemistry and Physics 2009; 9: 1263-1277.

Hallquist $M$, Wenger J, Baltensperger $U$, Rudich $Y$, Simpson $D$, Claeys $M$, et al. The formation, properties and impact of secondary organic aerosol: current and emerging issues. Atmos. Chem. Phys 2009; 9: 5155-5236.

Heringa M, DeCarlo P, Chirico R, Tritscher T, Dommen J, Weingartner E, et al. Investigations of primary and secondary particulate matter of different wood combustion appliances with a high-resolution time-of-flight aerosol mass spectrometer. Atmos. Chem. Phys 2011; 11: 5945-5957.

Hoffmann D, Tilgner A, linuma $Y$, Herrmann H. Atmospheric stability of levoglucosan: a detailed laboratory and modeling study. Environmental science \& technology 2009; 44: 694-699.

Jimenez J, Canagaratna M, Donahue N, Prevot A, Zhang Q, Kroll JH, et al. Evolution of organic aerosols in the atmosphere. Science 2009; 326: 1525-1529.

Jimenez JL, Jayne JT, Shi Q, Kolb CE, Worsnop DR, Yourshaw I, et al. Ambient aerosol sampling using the aerodyne aerosol mass spectrometer. Journal of Geophysical Research: Atmospheres (1984-2012) 2003; 108.

Jolleys M, Coe H, McFiggans G, Taylor J, O'Shea S, Le Breton M, et al. Properties and evolution of biomass burning organic aerosol from Canadian boreal forest fires. Atmospheric Chemistry and Physics 2015; 15: 3077-3095.

Jordan TB, Seen AJ, Jacobsen GE. Levoglucosan as an atmospheric tracer for woodsmoke. Atmospheric Environment 2006; 40: 5316-5321.

Lanz V, Alfarra M, Baltensperger U, Buchmann B, Hueglin C, Prévôt A. Source apportionment of submicron organic aerosols at an urban site by factor analytical modelling of aerosol mass spectra. Atmospheric Chemistry and Physics 2007a; 7: 1503-1522.

Lanz VA, Alfarra MR, Baltensperger U, Buchmann B, Hueglin C, Szidat S, et al. Source attribution of submicron organic aerosols during wintertime inversions by advanced factor analysis of aerosol mass spectra. Environmental science \& technology 2007b; 42: 214-220.

Luhar AK, Mitchell RM, Meyer C, Qin Y, Campbell S, Gras JL, et al. Biomass burning emissions over northern Australia constrained by aerosol measurements: II-Model validation, and impacts on air quality and radiative forcing. Atmospheric environment 2008; 42: 1647-1664.

May AA, Saleh R, Hennigan CJ, Donahue NM, Robinson AL. Volatility of organic molecular markers used for source apportionment analysis: measurements and implications for atmospheric lifetime. Environmental science \& technology 2012; 46: 12435-12444.

Middlebrook AM, Bahreini R, Jimenez JL, Canagaratna MR. Evaluation of composition-dependent collection efficiencies for the aerodyne aerosol mass spectrometer using field data. Aerosol Science and Technology 2012; 46: 258-271.

Mohr C, DeCarlo P, Heringa M, Chirico R, Slowik J, Richter R, et al. Identification and quantification of organic aerosol from cooking and other sources in Barcelona using aerosol mass spectrometer data. Atmospheric Chemistry and Physics 2012; 12: 1649-1665.

Morawska L, Jayaratne E, Mengersen $\mathrm{K}$, Jamriska M, Thomas S. Differences in airborne particle and gaseous concentrations in urban air between weekdays and weekends. Atmospheric Environment 2002; 36: 4375-4383.

Ng N, Canagaratna M, Jimenez J, Zhang Q, Ulbrich I, Worsnop D. Real-time methods for estimating organic component mass concentrations from aerosol mass spectrometer data. Environmental science \& technology 2010a; 45: 910-916.

Ng N, Canagaratna $M$, Zhang $Q$, Jimenez J, Tian J, Ulbrich I, et al. Organic aerosol components observed in Northern Hemispheric datasets from Aerosol Mass Spectrometry. Atmospheric Chemistry and Physics 2010b; 10: 4625-4641. 
Ortega A, Day D, Cubison M, Brune W, Bon D, de Gouw J, et al. Secondary organic aerosol formation and primary organic aerosol oxidation from biomass-burning smoke in a flow reactor during FLAME-3. Atmospheric Chemistry and Physics 2013; 13: 11551-11571.

Paatero $P$. The multilinear engine-a table-driven, least squares program for solving multilinear problems, including the $\mathrm{n}$-way parallel factor analysis model. Journal of Computational and Graphical Statistics 1999; 8: 854-888.

Paatero P, Hopke PK. Rotational tools for factor analytic models. Journal of Chemometrics 2009; 23: 91-100.

Paatero P, Hopke PK, Song $\mathrm{X}-\mathrm{H}$, Ramadan Z. Understanding and controlling rotations in factor analytic models. Chemometrics and intelligent laboratory systems 2002; 60: 253-264.

Paatero P, Tapper U. Positive matrix factorization: A non-negative factor model with optimal utilization of error estimates of data values. Environmetrics 1994; 5: 111-126.

Simoneit BR. Biomass burning-a review of organic tracers for smoke from incomplete combustion. Applied Geochemistry 2002; 17: 129-162.

Simoneit BR, Schauer JJ, Nolte C, Oros DR, Elias VO, Fraser M, et al. Levoglucosan, a tracer for cellulose in biomass burning and atmospheric particles. Atmospheric Environment 1999; 33: 173-182.

Sun Y-L, Zhang Q, Schwab J, Demerjian K, Chen W-N, Bae M-S, et al. Characterization of the sources and processes of organic and inorganic aerosols in New York city with a high-resolution timeof-flight aerosol mass apectrometer. Atmospheric Chemistry and Physics 2011; 11: 15811602.

Ulbrich I, Canagaratna M, Zhang Q, Worsnop D, Jimenez J. Interpretation of organic components from Positive Matrix Factorization of aerosol mass spectrometric data. Atmospheric Chemistry and Physics 2009; 9: 2891-2918.

van der Werf GR, Randerson JT, Giglio L, Collatz GJ, Kasibhatla PS, Arellano Jr A. Interannual variability in global biomass burning emissions from 1997 to 2004. Atmospheric Chemistry and Physics 2006; 6: 3423-3441.

Weimer S, Alfarra M, Schreiber D, Mohr M, Prévôt A, Baltensperger U. Organic aerosol mass spectral signatures from wood-burning emissions: Influence of burning conditions and wood type. Journal of Geophysical Research: Atmospheres (1984-2012) 2008; 113.

Zhao R, Mungall EL, Lee AK, Aljawhary D, Abbatt JP. Aqueous-phase photooxidation of levoglucosana mechanistic study using Aerosol Time of Flight Chemical Ionization Mass Spectrometry (Aerosol-ToF-CIMS). Atmospheric Chemistry and Physics Discussions 2014; 14: 8819-8850. 